\title{
Research on five Axis NC Machining Simulation Based on VERICUT
}

\author{
http://dx.doi.org/10.3991/ijoe.v11i7.4767 \\ Yuan Zhihua ${ }^{1}$,Wang Jipeng ${ }^{1}$ Kong Xiaolong ${ }^{1}$,Hu Yuhui ${ }^{2}$ \\ ${ }^{1}$ Shenyang Ligong University,Shenyang,China \\ 2 Shenyang Polytechnic College, Shenyang, China
}

\begin{abstract}
The structure of five axis machine tool is complex and expensive, especially in the processing of complex and sophisticated parts. It is prone to produce the phenomenon of overcutting or undercutting between the machine parts and the knives or the machine tool, which will cause serious damage or even grievous scrap on the machine tool . With the help of VERICUT 7.0 Simulation of NC machine tool, you can modify and optimize the NC program code, shortening the real processing time required and improving the economic benefit of the company remarkably.
\end{abstract}

Key word - VERICUT 7.0 five axis machine tool; NC; Simulation

\section{INTRODUCTION}

Dealing with some highly accurate and complicated parts which are demanded, for machine tool processing, due to the workpiece and cutting tool's interactive rotation, it is much more likely to cause the damage and even the scrap on workpiece, cutting tool or machine tool ${ }^{[2]}$, which leads to the stagnation of the whole production plan. This kind of damage could be avoided, but it expends too much time and human power. It requires repeated debug process, modifies the nc program, which causes a waste of time and money and the low work efficiency .

In recent years, the computer is developing on the aspects of hardware and software, especially the development and popularization of the computer simulation software, which makes changes of the mechanical processing from the traditional machine tool operation to the computer simulation processing. Simulation of the real machine tool processing is becoming more and more humanized and tends to be more realistic and vivid.

\section{VERICUT GENERAL SIMULATION OF MACHINING PROCESS}

Embedding MS Visio drawings causes problems while transforming the document into PDF format. It is better to export them to GIF (graphics, screenshots) or JPEG (photos) format.

(1)Open the VERICUT and establish a new project file. (2) Build a machine component tree , allocate machine tool processing of the origin and form the collision and axis movement limit interference check settings [3]. (3) Select machine tool numerical control system, set the $\mathrm{G}$ code configuration control system for simulation, and the parameters of control system. (4) Build the processing of cutter table. (5) Add to the manufacturing work piece, tooling, etc.
(6) Adjust the standard of NC processing program, tool radius compensation, length compensation, etc., as well as machine initialization position, and tool changing
position

(7) Choose CNC machining simulation program. (8) Start the simulating process in the system. (9) Analyze the simulating results and make use of automatic comparison's function to analyze overcutting and the remaining part, as well as the phenomena of collision and interference to generate the project document $^{[5]}$.

(10) Modify the NC manufacturing process and process, the machine tool to check whether it satisfy the requirements of the work pieces.

\section{BUILD DMU50 FIVE AXIS MACHINE TOOL MODEL}

In $U G$, according to the actual size of the real machine DMU50, we establish a virtual model of machine tool, and then export the STL file, in order to establish a machine tool simulation model in VERICUT. The exported STL file is mainly used for the required simulation linear axis and the axis of rotation in VERICUT, etc. For those which does not require the simulation of machine shell device, control panel, and some control systematic parts, we shall not export. Finally the model is shown in figure 1.

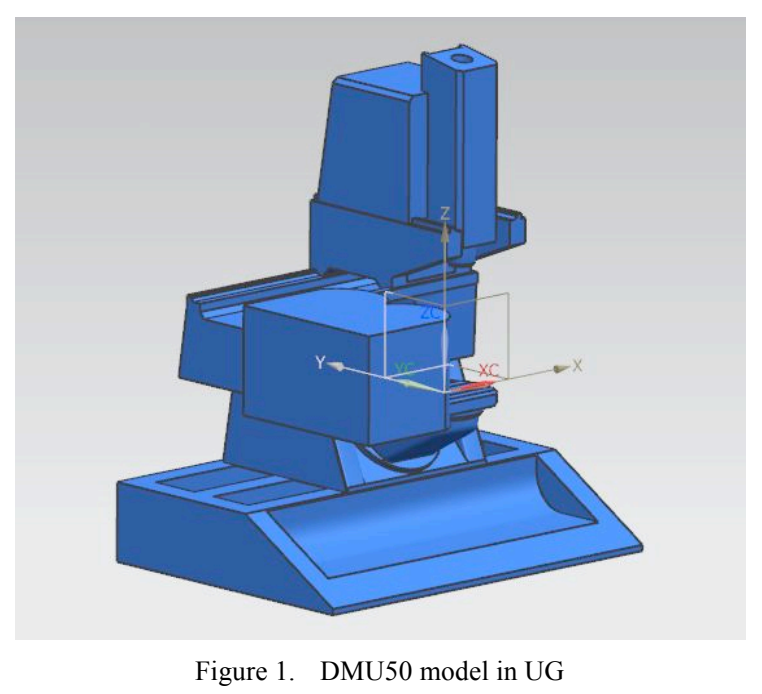

A. Build a virtual machine component tree

Build new project file and machine tool component tree. According to the real structure of DMU50 NC 
PAPER

RESEARCH ON FIVE AXIS NC MACHINING SIMULATION BASED ON VERICUT

machining center, we define the component tree and the component of machine tool in the component tree. It concludes machine tool, $\mathrm{X}$ axis and $\mathrm{Y}$ axis and $\mathrm{Z}$ axis, Spindle, cutting tools, machine tools $>\mathrm{B}>\mathrm{C}$ component tree, as shown in figure 2.

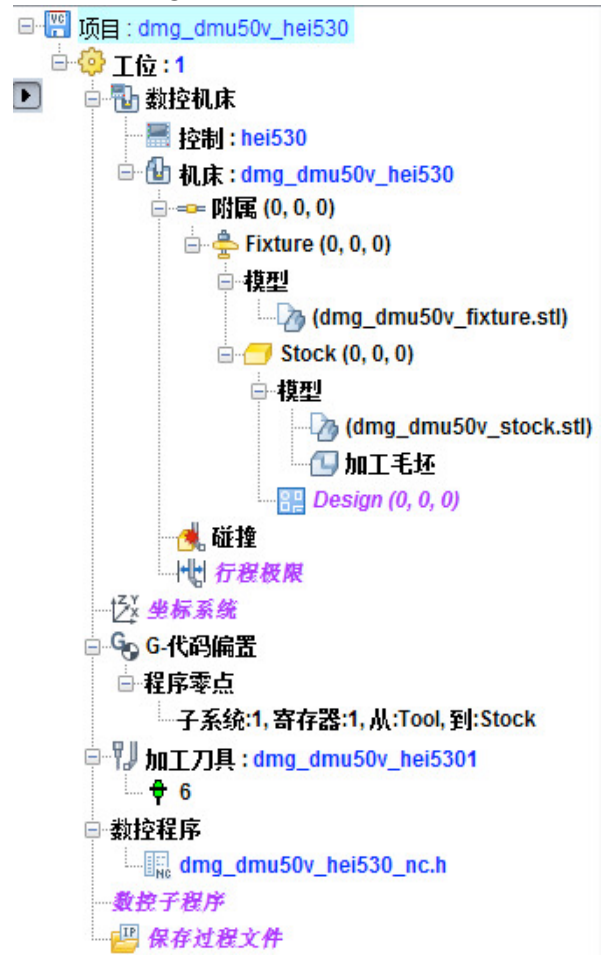

Figure 2. DMU50 component tree

\section{$B$. The determination of machine system parameters}

Create a machine component tree is completed, can't we simulate parts processing, to initialize the Settings. (1) Collision detection parameter Settings, as shown in figure 3 .

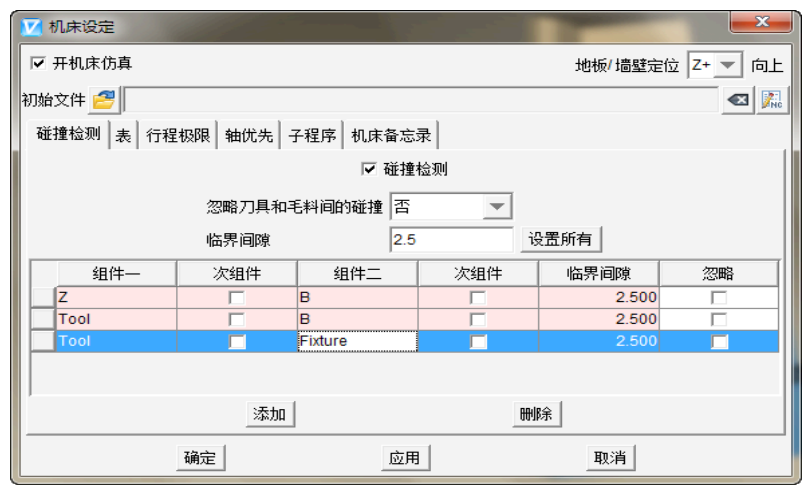

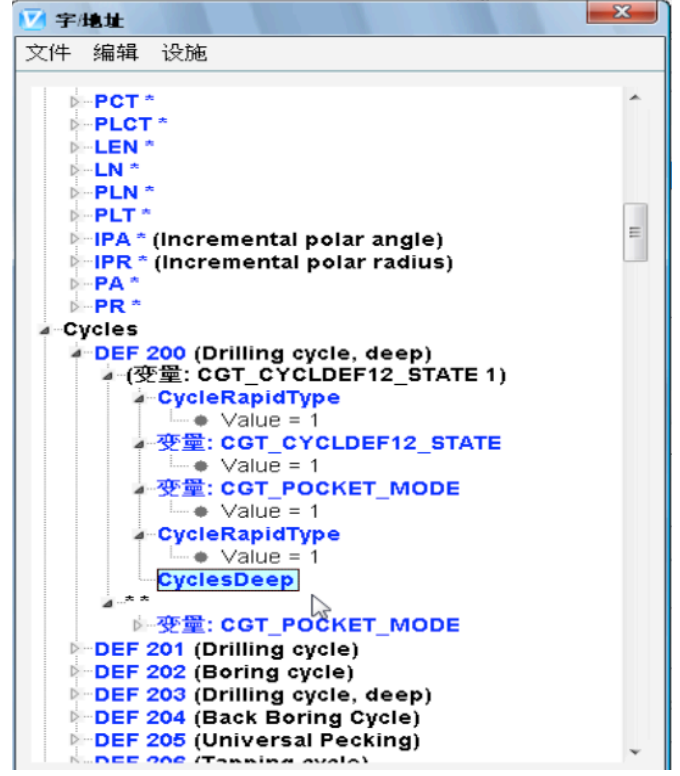

Figure 3. Collision detection parameter Settings

(2) Sets the initial value of the machine tool to $(250,150$, 542).Machine stroke limit set as shown in figure 4.

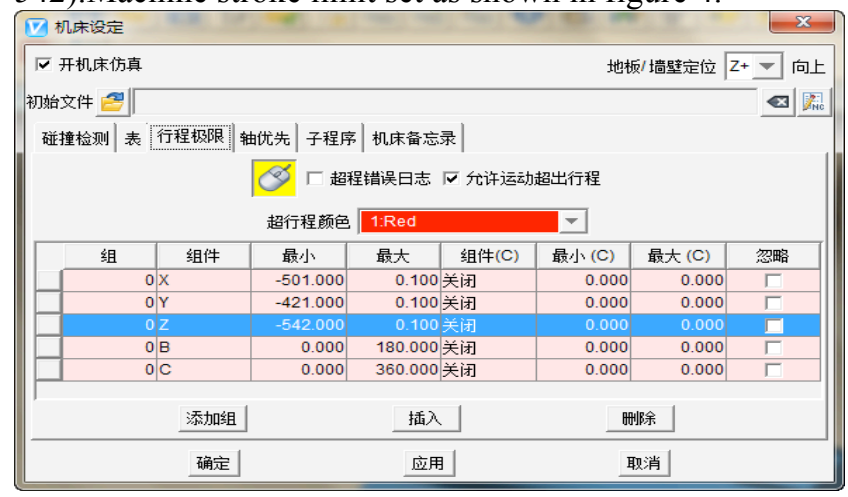

Figure 4. Machine limits set itinerary

\section{The establishment of the machine tool magazine}

In the tool manager, create the corresponding machining tool library, including tool clamping, tool holder, cutting, etc.,.As shown in figure 5 tool library.

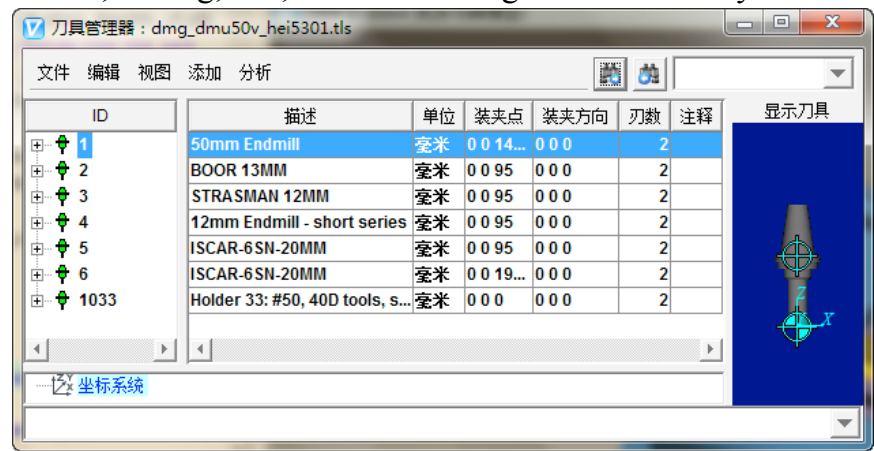

Figure 5. Build tool library

\section{The choice of machine tool control system}

Set up the composition and structure of machine tool and the setting of initial parameters, the stroke limit set, to achieve processing movement, also need to the digital control machine tool configuration system, make the machine interpretation of nc code, interpolation algorithm, 
the simulation shows that the basic function such as. The machine chooses dmu50 - hei530 CNC system ${ }^{[6]}$.

\section{E. Selection process, zero offset configuration $G$ code}

Complete the choice of data control system, also need to zero, the setup program in order to determine the zero position of process.As shown in figure 6 .

\begin{tabular}{|c|c|c|}
\hline \multicolumn{3}{|c|}{ - 选择从到定位 } \\
\hline 特征 & 名字 & \\
\hline 组组件 & Tool & $\nabla$ \\
\hline \multicolumn{2}{|c|}{ 调整从位置 000} & S \\
\hline 到组件 $\quad \nabla$ & Stock & $\nabla$ \\
\hline \multicolumn{2}{|c|}{ 调整到位置 000} & 5 \\
\hline \multirow[b]{2}{*}{ 计算相对位置 } & (XYZABCUWWABC) & \\
\hline & 000 & \\
\hline 额外的偏置 & 0000 & \\
\hline ○输入偏置（或 & 选择两点) & \\
\hline
\end{tabular}

Figure 6. Zero configuration program

\section{SimUlATION MACHINING SIMULATION}

After setting all the parameters, simulation of machining processing. To observe the whole movement of machine tools and cutting tools and machine tool for cutting the collision and interference in the machine tool components interference, colliding, distance, the phenomenon such as cutting, during processing of various parts of the problem are highlighted in red, and in the information column shows the error message, show the conditions of the mistakes and the line of $\mathrm{CNC}$ programming problem.After the completion of the simulation program to automatically generate a log file.Including the simulation of errors, warnings, etc., such as tool path simulation display name, start and the end of the error of the error and warning, etc. ${ }^{[7]}$.

After repeated debug on the CNC programming, direct no errors or warning, shows that the simulation model has reached the requirement of design precision.As shown in figure 7 .

\section{THE ACTUAL PROCESSING VALIDATION}

In order to further demonstrate the validity of VERICUT numerical control program, carry on the processing on the real machine, finally get the precision of parts.DMU50 nc machine tools through actual five-axis linkage machining simulation, the operator can before making the actual machining, $\mathrm{CNC}$ program and machine tool path optimization and debugging, reduce staff for numerical control machining center adjustment time, improve business efficiency.

\section{REFERENCES}

[1] Wei Lin,"The research of nc machining simulation system based on VERICUT," Shenyang ligong University. Shneyang, 2008.

[2] Zeng Qiang,Zhang Zhisen,Xiao Huijin, "Based on VERICUT five-axis linkage nc machining simulation," Science technology and engineering, 2012.

[3] Song Jiany, "Based on the CY - VMC850 type machining center of the construction of the virtual nc machining system," Journal of mechanical engineering, 2012.
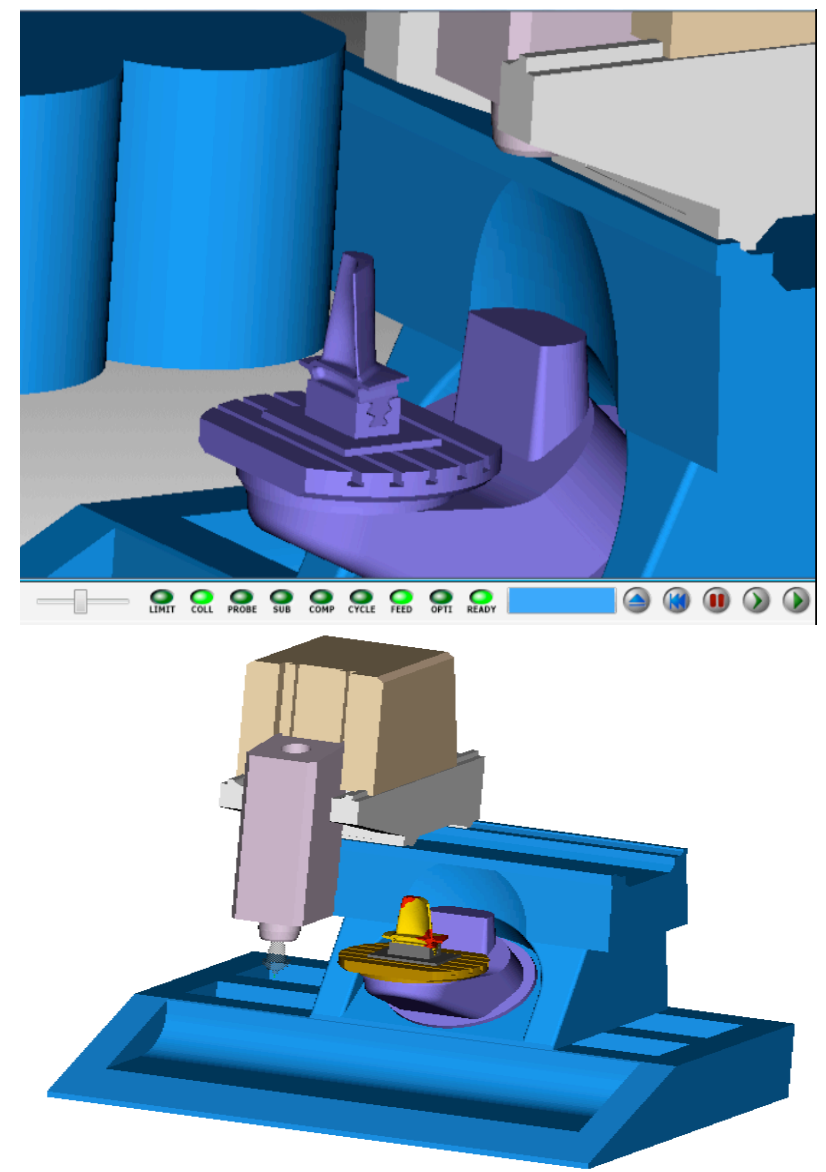

Figure 7. The simulation process error display

[4] Jiang Yan,Shi Ping, "engineering, 2012. [4] kang yeon, ShiPing. Spher mill compensation algorithm of five-axis linkage machining of free surface," Harbin industrial university, 2012.

[5] Song Jianyi, "Based on the CY - VMC850 type machining center of the construction of the virtual nc machining system", Journal of mechanical engineering, 2012.

[6] Zeng Qiang, "Five-axis linkage nc machining of impeller parts and simulation," Southwest jiaotong university, 2009.

[7] Zeng Qiang, "Five-axis linkage nc machining of impeller parts and simulation," Southwest jiaotong university, 2009.

\section{AUTHORS}

Yuan Zhi-hua is with the Shenyang Ligong University, $\mathrm{PhD}$, supervisor of postgraduate, major research artillery, automatic weapons and ammunition.(email:yuanzhihua2003@yeah.net)

Wang Jipeng, was with the Shenyang Ligong University, graduate student, majoring in terminal ballistic and damage theory, (email:bigbird123456789@163.com)

Kong Xiaolong, was with the proving ground LiaoShen industrial group co., LTD, (e-mail: 984206136@qq.com)

Li Zhengzhi is with the Electrical Engineering Department, University of Colorado, Boulder, CO 80309 USA, on leave from the National Research Institute for Metals, Tsukuba, Japan (e-mail: author@nrim.go.jp

Submitted 25 May 2015. Published as resubmitted by the author 25 june 2015 . 